\title{
Stakeholders' Perceptions of the EU ETS Revision and Development
}

* Institute of Environmental Protection - National Research Institute;

e-mail: maciej.cygler@kobize.pl

Keywords:

climate policy, EU ETS, stakeholders, carbon markets, EU ETS extension

\section{Abstract}

The European Green Deal (EGD) communication supports strengthening and expansion of the European Union Emissions Trading System (EU ETS). Possible linkages with other carbon markets worldwide are also subject to both experts' and policy-makers' discussions. Results of the survey on the state and expectations concerning the development of the EU climate policy measures, in particular, the EU ETS, are presented in this article. The survey was done online. There is a group of questions dealing with the EU ETS performance and future development, and another concerning available information assessment and individual self-assessment in terms of relevant knowledge.

(c) IOŚ-PIB

\section{INTRODUCTION}

The EU ETS has been recognised as the cornerstone of the EU climate policy for more than last 15 years. It has evolved into one of the largest and most mature carbon markets in the world. After many years of low European Union Allowance (EUA) prices, since the turn of 2017 and 2018, they began to rise, reaching the level of 50-60 euros in $2021^{1}$. At this point, we do not address the causes of this growth, both internal and external, but attempt to examine how the future of the system is perceived. The EGD clearly emphasises the way towards strengthening and expansion of the EU ETS ${ }^{2}$. Although the European Commission Communication on the EGD (2019) is still being transformed into specific regulations, the future picture of the EU ETS seems to be inevitable. Moreover, besides its development within the $\mathrm{EU}$, including interactions with other climate policy measures, we should also consider its possible future linkages with other carbon markets, responding to expectations in global climate policy addressed in the Paris Agreement. The climate policy ambition, both within the EU as well as on the international level, has been rapidly increasing over the last years, creating many challenges for all actors. The main purpose of this study is to analyse

1 See market data by European Energy Exchange (EEX).

$\mathbf{2}$ The European Green Deal can be recognised as a way to sustainable economies, a road map for making the EU's economy sustainable by dealing with climate and environmental challenges as to make the transition acceptable and inclusive for all. It was communicated by the European Commission on 11 December 2019.
Poland's stakeholders' perceptions of the EU ETS revision and development, including identification of main gaps in their relevant knowledge, opinions and expectations, with special emphasis on the EU ETS interactions with other EU climate policy measures and other carbon markets in the world ${ }^{3}$.

\section{METHODICAL APPROACH}

The survey was made applying the questionnaire addressed to an identified target group representing the key EU ETS stakeholders in the context of this system revision and development. The target group includes administration, directly and indirectly involved in the process of development and implementation of relevant measures, local authorities involved in the implementation and experiencing impacts of the policy changes, research entities engaged in the policy options' development and impact assessment, think-tanks and non-governmental

3 The survey has been made as a part of the LIFE VIIEW 2050 project to support the best possible adjustment of the project outputs to its target group expectations. The project has been implemented by the Centre for Climate and Energy Analyses (CAKE), being a part of the National Centre for Emissions Management (KOBiZE). The main project objective is to assess the functioning of the EU ETS, its interaction with other EU policy measures, other international emissions trading systems and its further development concerning a climate-neutral EU economy by 2050. (more on the project at https:// climatecake.ios.edu.pl/?lang=en; accessed on 17 September 2021). 
Table 1. Survey replies distribution by stakeholders' group

\begin{tabular}{|c|c|}
\hline $\begin{array}{c}\text { Stakeholders' group } \\
\text { Governmental administration involved in climate policy development and } \\
\text { implementation }\end{array}$ & $\begin{array}{c}\text { Share in the survey population } \\
(27,5 \%)\end{array}$ \\
\hline $\begin{array}{c}\text { Governmental administration involved in the EU ETS implementation } \\
\text { Governmental administration not directly involved in climate policy } \\
\text { development and implementation }\end{array}$ & $10(9,2 \%)$ \\
\hline Local authorities & $8(7,3 \%)$ \\
\hline Public research centre providing climate policy assessment & $4(3,7 \%)$ \\
\hline Non-governmental think-tanks providing climate policy assessment & $18(16,5 \%)$ \\
\hline Non-governmental organisation - climate policy & $11(10,1 \%)$ \\
\hline Other & $8(7,3 \%)$ \\
\hline
\end{tabular}

Source: own study

organisations contributing to impact assessment and lobbying activities. This attitude to identifying the survey sample can be recognised as non-probability and convenience sampling (Young 2016). It has been chosen to collect replies from precisely predefined respondents only, avoiding opinions of a wider public, assuming their insufficient knowledge on highly complex policy measures, and then irrelevant in terms of these measures technical dimension. Replies have been garnered from 109 respondents (104 from Poland). The survey sample distribution is presented in Table 1.

The survey ran from 20 March to 30 April 2021. Using LimeSurvey, a web-based survey tool, respondents had the opportunity to answer two groups of closed questions first dealing with assessment and expectations concerning the EU ETS development and its interactions, while the second focussed on respondents' relevant knowledge selfassessment.

\section{RESULTS}

The first group of the survey questions is focussed on the evaluation of both the current performance of the EU ETS as well as of its expected extension and development. The following key questions have been asked in this section:

- What is your opinion on the EU ETS effectiveness in reaching the EU climate policy emission reduction targets?

- In your opinion, should the EU ETS be extended to new sectors (e.g. construction, transport, international aviation, municipal and housing sector)?

- Do you think the EU ETS should be integrated with other similar systems in the world, striving for a global emissions trading system?

Results are presented in the figures below. Figure 1 shows the respondents' opinions on EU ETS effectiveness in reaching the EU climate policy targets. More than $73 \%$ of the stakeholders support the opinion that the EU ETS is an essential measure to reduce greenhouse gas emissions, while $15 \%$ recognises it as a highly effective and essential measure. Certain progress in supporting EU ETS improvement can be emphasised rather than opposing this policy measure, while we look at earlier Poland's stakeholders' attitudes. In the mid-2010s, Poland was seen as one of the main stumbling blocks and used its special situation of energy system heavily reliant on coal to justify such a position (Wettestad 2014). However, more than one-fourth still perceives the system as ineffective, what is more than in Carbon Survey 2019 (Refinitive 2019) made for the group representing more countries, where only $14 \%$ said that the EU ETS does more harm than good, while the rest accepts its usefulness, including $24 \%$ supporting the opinion that EU ETS is the best policy option.

Respondents' opinions concerning the proposed extension of the EU ETS is presented in Figure 2. Almost $67 \%$ of respondents supported the European Commission's proposals to extend the system (introduce construction, transport, international aviation, municipal and housing sector). Although we are not sure about the motivation behind such an opinion, such a high acceptance level seems to correspond with the positive assessment of the EU carbon market. It should be noted, however, that the survey was made before publication of the system extension details and relevant impact assessment, including costs. Moreover, the share of respondents with a negative attitude towards the EU ETS extension is higher than those supporting its usefulness and performance as a policy measure in general $33 \%$ versus $26 \%$, respectively).

The third key question concerning the EUETS development moves to an international dimension of carbon markets and its possible linking with other emission trading systems in the world. This is not yet a proposal of the European Commission, but in the context of the dynamics of global climate policy and efforts to raise the policy 


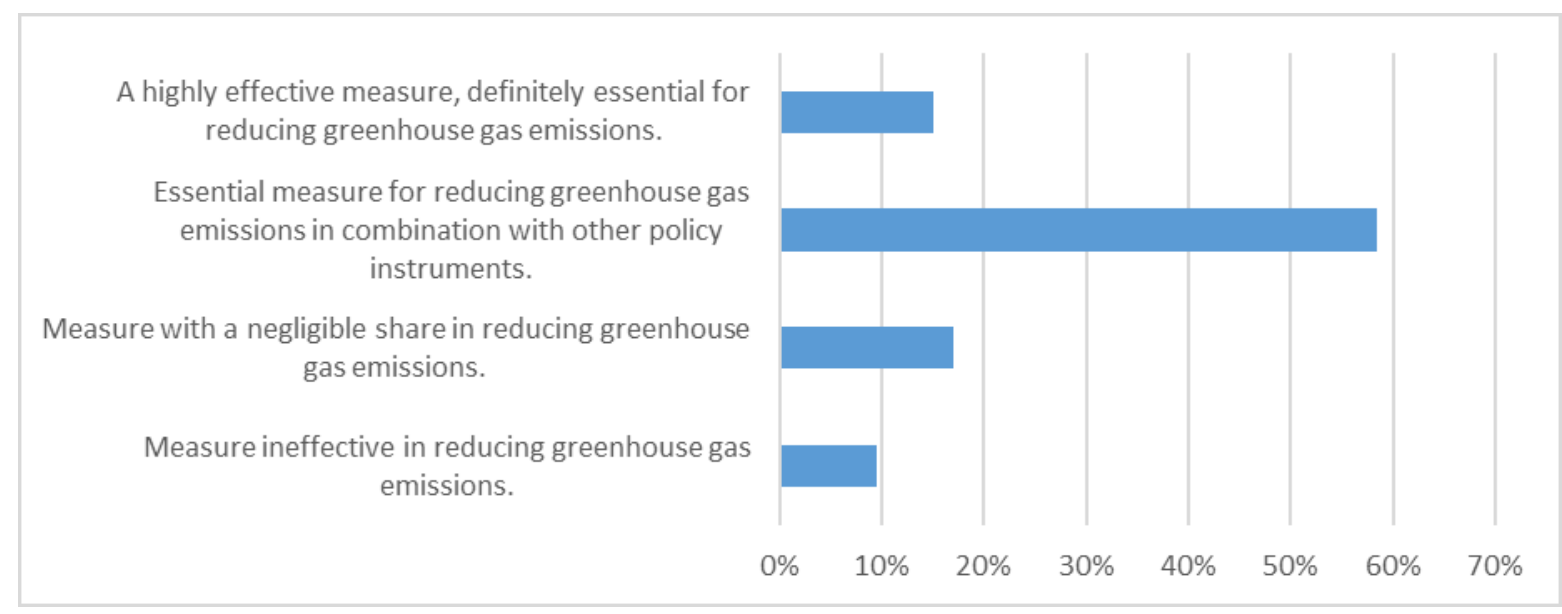

Figure 1. Respondents' replies to the question "What is your opinion on the EU ETS effectiveness in reaching the EU climate policy emission reduction targets?" (Source: own study)

No, the scope of the EU ETS should even be limited.

No, the EU ETS should remain within its current scope.

Yes, but to a limited extent.

Yes, it should definitely cover as many sectors as possible.

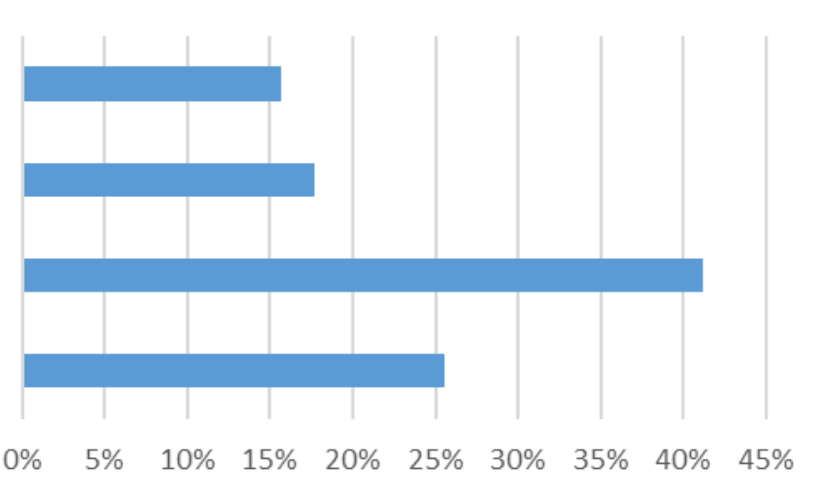

Figure 2. Respondents' replies to the question "Should the EU ETS be extended to new sectors (e.g. construction, transport, international aviation, municipal and housing sector)?" (Source: own study)

ambition level in world regions, linking carbon markets and therefore carbon prices convergence is considered probable. Besides, such actions can be effective in the context of correcting the EU ETS imperfections and defects. More than $82 \%$ of respondents support the concept of carbon markets linking, including 55\% backing a global carbon market option. Such an attitude corresponds with the opinion of many economists and policy experts, that the carbon price is the best way to achieve global climate policy goals effectively and efficiently ${ }^{4}$.

Before passing to questions concerning the respondents' personal knowledge self-assessments, they were asked to evaluate satisfaction in terms of adequate information availability regarding the EU ETS. It should be reminded here that the survey was addressed to professionals

4 See Economists' Statement on Carbon Pricing (https://www.eaere. org/wp-content/uploads/2019/06/statement.pdf; accessed on 18 September 2021) involved directly or indirectly in climate policy development, implementation and/or assessment, thus actively searching and using this kind of information. There were no answers confirming information unavailability, and only less than $20 \%$ of respondents were unsatisfied, supporting the opinion that information on the EU ETS was incomplete, incomprehensible and/or inconsistent, while a clear majority was satisfied. This result is important in terms of the general reliability of opinions collected in the first group of questions.

The final section of the survey included questions relating to the respondents' knowledge of climate policy measures, specifically the EU ETS functioning and future developments. The following key questions were asked in this section:

- Can you say that you understand the mechanism and economic rationale of the emission trading systems?

- How do you assess your personal knowledge of the EU ETS? 


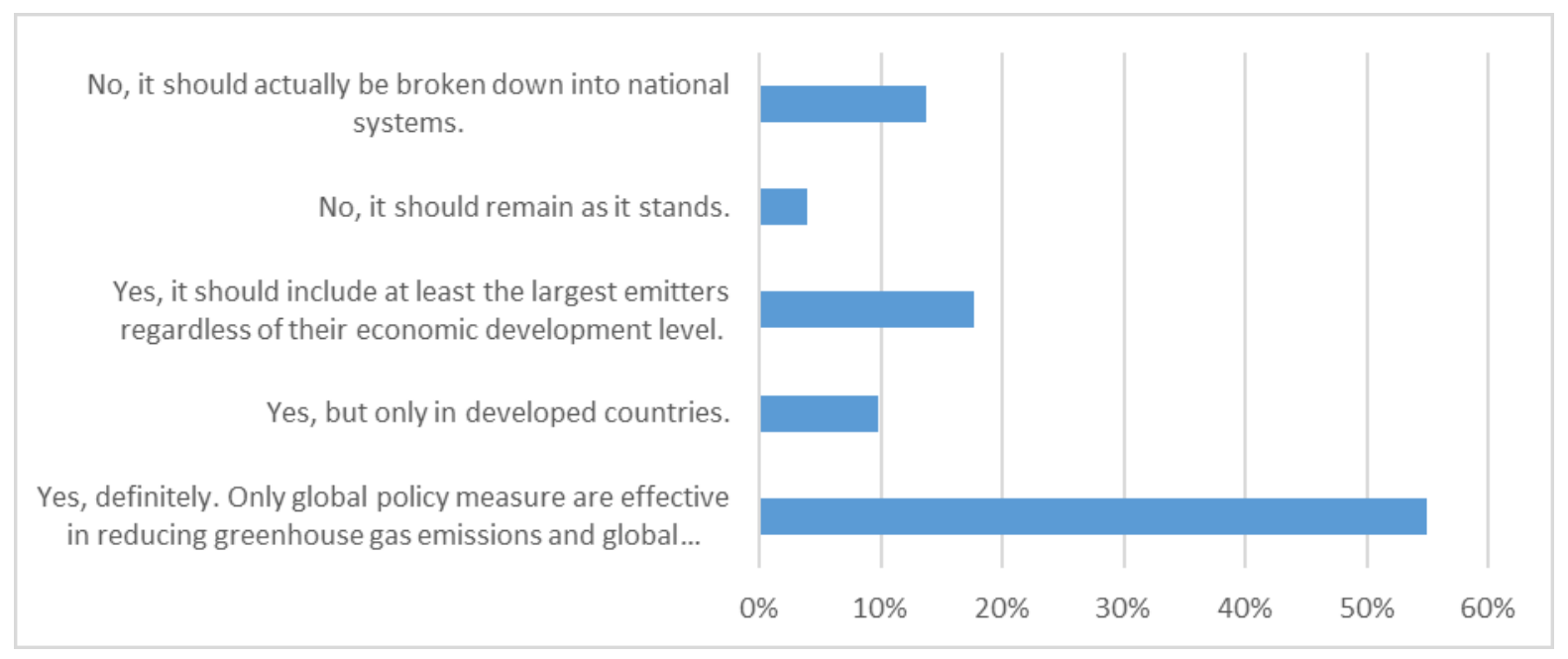

Figure 3. Respondents' replies to the question "Do you think the EU ETS should be integrated with other similar systems in the world, striving for a global emissions trading system?" (Source: own study)

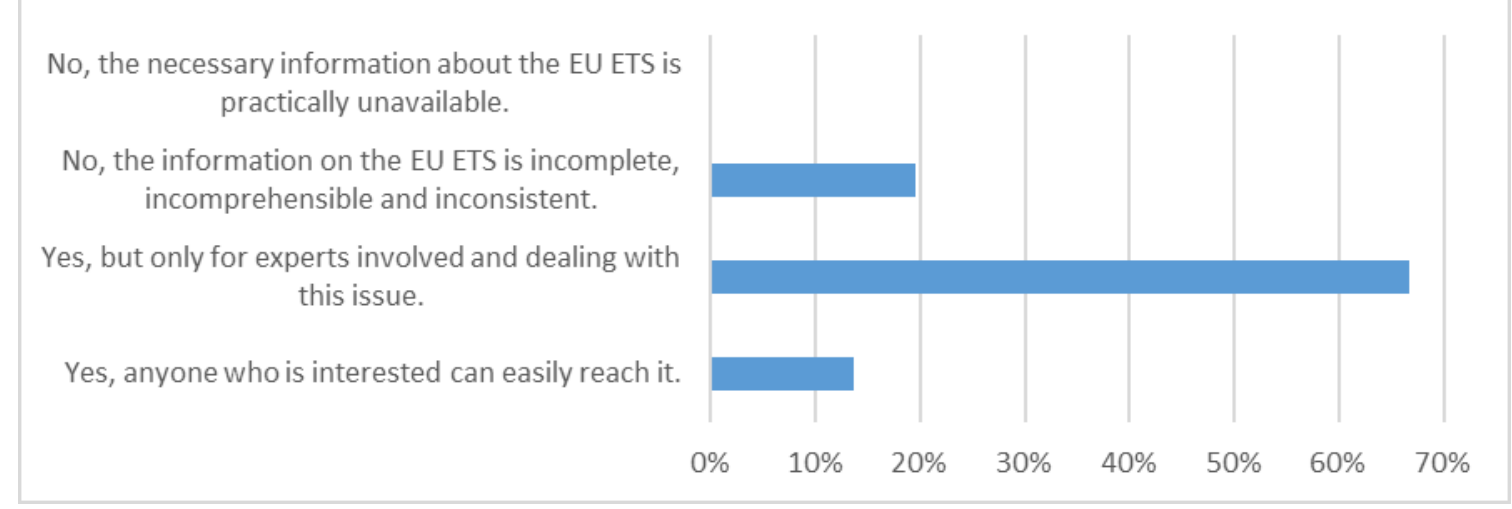

Figure 4. Satisfaction level concerning the available information on the regulations, rules and functioning of the EU ETS. (Source: own study)

- How do you assess your knowledge of the EU ETS interaction with other EU climate policy measures (e.g. on renewable energy, energy efficiency and others)?

- How do you assess your knowledge of the current and future integration of the EU ETS with other emission trading systems in the world?

It should be reminded here that respondents have had an opportunity to subjectively assess their knowledge, and this survey did not verify the answers. However, the context of the survey as well as its main objectives, justifies our assumption that answers in this section can be considered reliable. Figure 5 shows that $95 \%$ of respondents understand the mechanism of the emission trading in general, and $75 \%$ also recognise its economic rationale.

The picture changes when the question explicitly addresses the EU ETS. Only 53\% of stakeholders believe they have got extensive and sufficient knowledge (Figure 6). Almost half declared that their knowledge is unsatisfactory, regardless of the level of EU ETS contribution to professional responsibilities. This result contributes to the opinion that although emission trading in general is not confusing, the EU ETS has become highly complex over time what reduced the share of stakeholders satisfied in terms of relevant knowledge (Perino 2018).

The next two questions corresponded with the EU ETS interactions. The EU climate policy was implemented by a mix of measures, all contributing to goals achievement (e.g. renewables and energy efficiency). Precise evaluation of their individual effectiveness is challenging, also because of complex interactions between the EU ETS and other measures. Figure 7 shows that the share of highly satisfied respondents is decreasing compared to previous questions. Less than a half believes they know enough as far as climate policy measures and their interactions with the EU ETS are concerned. One-fourth is experienced in various EU climate policy measures, however, does 
I don't know what emissions trading is all about.

I understand the trade mechanism, but I do not understand the economic rationale of the system.

Yes, the mechanism and the economic rationale are clear and understandable to me.

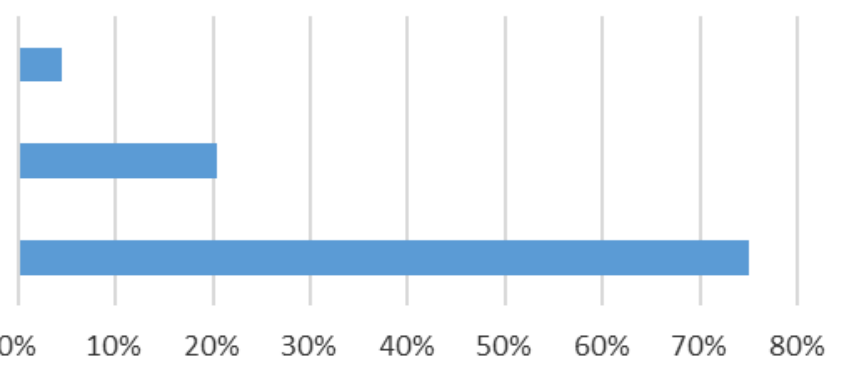

Figure 5. Understanding the mechanism and economic rationale of the emission trading systems. (Source: own study)

My knowledge on this subject is rudimentary and I am not going to change it.

My knowledge on this subject is rudimentary and I am looking for an opportunity to extend it.

I have got unsatisfactory knowledge on this subject, but it does not bother me in my duties.

I have got unsatisfactory knowledge on this subject, what makes performing my relevant duties difficult.

I have got an extensive knowledge on this subject, although professionally it does not directly concern me.

I have got an extensive and sufficient knowledge on this subject, my work is related to it.

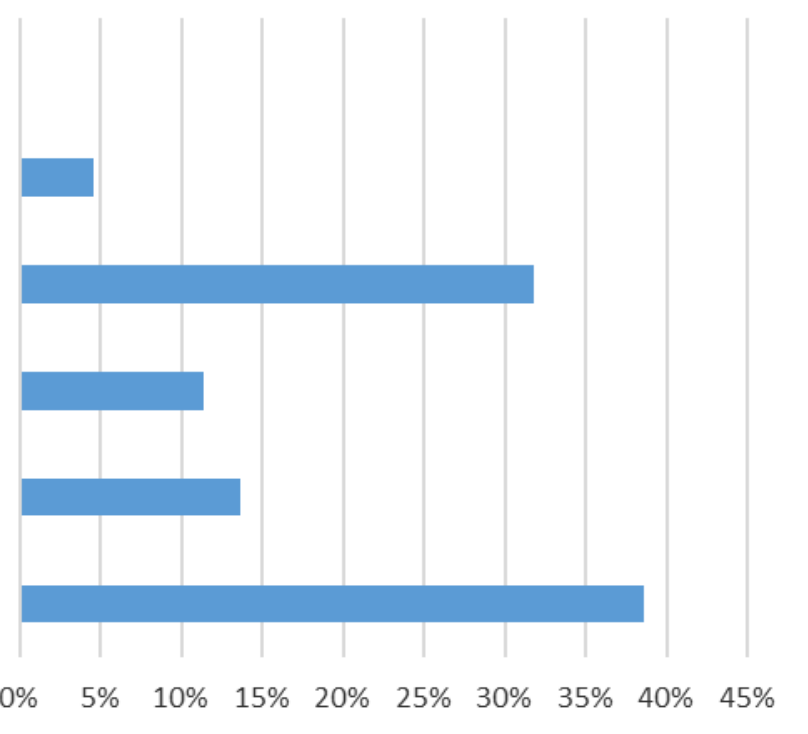

Figure 6. Evaluation of individual knowledge of the EU ETS. (Source: own study)

Knowledge of the interaction of the EU ETS with other climate policy measures is unnecessary to me, it only applies to experts working in this field.

My knowledge of the EU climate policy measures is insufficient and needs to be improved.

I have got an extensive knowledge of the various EU climate policy measures, but know little about their interaction with the EU ETS.

I have got a satisfactory knowledge of other climate policy measures and their interaction with the EU ETS.

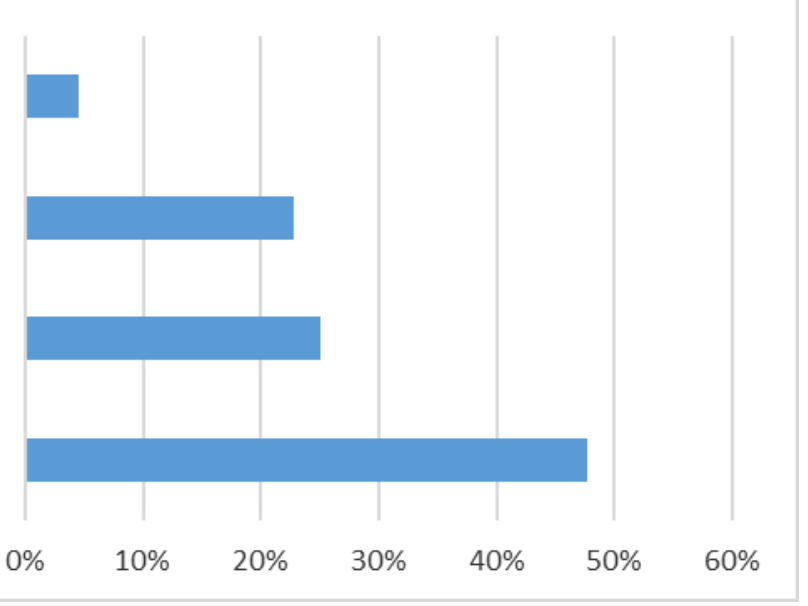

Figure 7. Evaluation of own knowledge concerning the EU ETS interaction with other EU climate policy measures. (Source: own study) 
I have not heard about the option of linking the EU ETS with other similar systems in the world.

I am aware of such a possibility, but I do not know the details.

I know a lot about this, I follow the information on a regular basis.

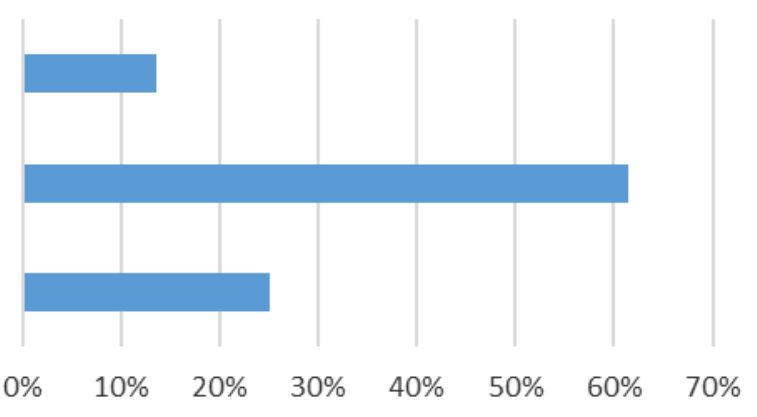

Figure 8. Evaluation of knowledge of the current and future integration of the EU ETS with other emission trading systems in the world. (Source: own study)

not confirm an appropriate knowledge about mutual interactions.

The final question regarded the possible future integration of the EU ETS with other emission trading systems in the world. While $88 \%$ of respondents declared they were familiar with the concept, only $25 \%$ believed they knew a lot about it (Figure 8).

\section{CONCLUSION}

Survey results prove a quite significant stakeholder support to the EU ETS and its further development, including the system extension and linking with other carbon markets worldwide. More than $73 \%$ of the stakeholders recognise the EU ETS as a key policy measure to reduce greenhouse gas emissions, while $15 \%$ perceive it as a highly effective and essential measure. Nevertheless, one-fourth still sustain their criticism, identifying the EU ETS as ineffective and suggest even its breakdown or at least keeping the current scope, avoiding any extension. Although this negative opinion does not dominate in replies, it should be addressed in the system revision and development. The same can also be learned from replies supporting the EU ETS extension towards new sectors, mainly buildings and transport, that represent a slightly lower share than the generally positive perception of this measure. While support to extending the system reaches $67 \%$, one-third still oppose this option. Regardless of quite a significant share of criticism concerning the EU ETS performance so far and its further development within the EU, 82\% of respondents support the concept of carbon markets linking worldwide, while $55 \%$ believe the global carbon market should be implemented. That corresponds with the opinion that the carbon price is the best way to achieve global climate policy goals effectively and efficiently.

A high level of knowledge concerning climate policy, and specifically the EU ETS, has been recorded in the survey population. The vast majority of respondents believe they understand the mechanism of emission trading in general and also recognise its economic rationale (95\% and 75\%, respectively). Nevertheless, around 50\% of replies emphasise the need to extend and improve the knowledge on interactions between the EU ETS, alternative climate policy measures, and other carbon markets worldwide. Such a result identifies a gap in terms of adequate information availability and justifies efforts to generate and disseminate this kind of knowledge in the stakeholders' group.

\section{REFERENCES AND LEGAL ACTS}

European Commission (2019), European Green Deal. Communication from the Commission. COM (2019) 640 final.

PERINO, G. (2018), New EU ETS Phase 4 rules temporarily puncture waterbed. Nature Climate Change, 8, 260-271. Refinitive Carbon Market Survey (2019), Refinitiv Eikon.

WETTESTAD, J. (2014), Rescuing EU Emissions Trading: Mission Impossible? Global Environmental Politics, 14 (2): 64-81.
YOUNG, T. J. (2016), Questionnaires and Surveys. [in:] Zhu Hua [ed.], Research Methods in Intercultural Communication: A Practical Guide. Wiley Blackwell, 163180. 